\title{
Риски, связанные с качеством премиксов, и их профилактика
}

Околелова Т.М., доктор биологических наук, профессор, Заслуженный деятель науки РФ

Енгашев С.В., доктор ветеринарных наук, профессор, академик РАН

Лесниченко И.ю., кандидат ветеринарных наук

ООО «НВЦ Агроветзащита»

Шевяков А.Н., кандидат биологических наук

Хребтова Е.В.

ФГБНУ Федеральный научный центр «Всероссийский научно-исследовательский и технологический институт птицеводства» Российской академии наук (ФНЦ «ВНИТИП» РАН)

\begin{abstract}
Аннотация: Рассмотрена роль качества премиксов 6 питании птицы 6 сбязи с реализацией ее генетического потенциала продуктивности. Приведены особенности побышенной чубствительности птиць к недостатку витаминов. Описаны фракторы, блияющие на потребность птиць $\mathcal{6}$ битаминах и некоторых микроэлементах. Приводятся критерии биологической полноценности инкубационных яии различных видов сельскохозяйственной птиць и ориентировочные показатели обеспеченности птиць витаминами по их содержанию 6 печени (Витамины $A$ и E). Рекомендобано контролиробать обеспеченность птиць битамином $D_{3}$ по минерализации костяка и даны ориентировочные показатели содержания золь, кальция и фосфрора 6 костях у бысокопродуктивной птицы разных бидов и направления продуктибности. Обобщень данные по обеспеченности птиць битаминами, полученные при анализе печени, яии, костяка. Обращено внимание на причины низкой обеспеченности птицы витаминами $A, B_{2}, D_{3}$ и даны рекомендации по профилактике гиповитаминозов, бключающие, прежде бсего, контроль содержания битаминов 6 премиксах и биологических объектах (яйцо, печень, костяк), а также применение бодорастборимых битаминных комплексов для экстренной быпойки при гиповитаминозах.
\end{abstract}

Ключевые слова: сельскохозяйственная птица, битамины, премиксы, гиповитаминозы, печень, яйцо, кости.

Сбалансированное кормление сельскохозяйственной птицы немыслимо без обогащения комбикормов биологически активными и минеральными веществами. Прежде всего это относится к витаминам и микроэлементам, которые входят в число нормируемых показателей. Повышенная чувствительность птицы к недостатку витаминов в кормах связана с ее биологическими особенностями: высокая скорость роста и яичная продуктивность, вынос витаминов и микроэлементов с яйцом, быстрое продвижение корма по желудочно-кишечному тракту, недостаточный синтез и ограниченное всасывание эндогенных витаминов в пищеварительном тракте и т.п.

На потребность птицы в витаминах и микроэлементах оказывает влияние включение в рецептуру комбикормов наиболее дешевых ингредиентов при исключении или уменьшении доли богатых витаминами и микроэлементами продуктов переработки рыбы и мяса, качественных продуктов микробиологического синтеза. Разные виды тепловой обработки кормов, применение зерна повышенной влажности и нестабилизированных жиров, хранение кормов при высокой температуре и влажности, их контаминация микотоксинами также увеличивают потребность птицы в витаминах.
Неравномерное поступление витаминов и микроэлементов в организм часто связано с плохой гранулометрией компонентов и с низким качеством их смешивания при производстве комбикормов (старое оборудование), с расслоением последних при транспортировке и в процессе кормораздачи.

Проблема обостряется в случае возникновения стрессовых ситуаций, снижающих потребление корма и воды и уменьшающих кишечную абсорбцию витаминов и микроэлементов (повышенная температура, вакцинация, дебикирование, рассадка цыплят по ярусам, отлов и транспортировка птицы при переводе из зоны выращивания ремонтного молод- 
няка в цеха для взрослого поголовья и т.п.). Субклинические и клинические заболевания птицы, например кокцидиоз, дисбактериоз и т.п. также ослабляют абсорбцию витаминов и минералов в кишечнике. Потребность птицы в витаминах и микроэлементах изменяется под влиянием интенсивной селекции на повышение скорости роста, яичной и мясной продуктивности, при использовании в комбикормах антибиотиков, наличии в них антивитаминов и плесневых грибов, неодинаковой способности птицы различных пород, кроссов и возрастов к эндогенному синтезу витаминов. Нельзя не учитывать и наличие антагонистических и синергических взаимодействий между витаминами и микроэлементами.

При производстве инкубационных яиц следует иметь в виду, что эмбрионы птицы развиваются в яйцах, куда приток питательных и биологически активных веществ в процессе эмбриогенеза невозможен. Поэтому нарушение витаминного и микроминерального питания несушек и петухов ведет к снижению оплодотворенности и выводимости яиц, жизнеспособности птенцов после вывода. Очень часто приходится сталкиваться с повышенными показателями ранней эмбриональной смертности (недостаток витаминов A, Е), с гибелью эмбрионов на последней стадии развития и плохим окостенением клюва и ног (недостаток витамина $D_{3}$ ), курчавостью оперения и его обесцвечиванием (недостаток витамина $\mathrm{B}_{2}$ ). Нередки случаи мочекислого диатеза у эмбрионов и суточных цыплят (нарушения в кормлении несушек, включая обеспеченность витамином A) и т.п. [1-25].

Нельзя забывать, что на формирование скорлупы несушка использует до 25\% кальция из ме- дуллярной кости, поэтому восстановление ее запасов зависит не только от уровня и качества источников кальция и фосфора в комбикормах, но и от уровня витамина $\mathrm{D}_{3}$ и его биологической доступности, от состояния печени и почек, где происходит образование физиологически активной формы витамина $D_{3}$.

B настоящее время премиксная и комбикормовая промышленность работают исключительно на импортных витаминных препаратах, которые не всегда соответствуют физиологическим потребностям птицы по биологической доступности (разный состав структурообразующих компонентов), при этом некоторые препараты могут иметь низкую стабильность в составе премиксов, возможно, используются препараты с истекшим сроком годности. Поэтому проблема гиповитаминозов актуальна, как с позиций жизнеспособности, воспроизводства и полной реализации генетического потенциала продуктивности птицы, так и с позиций получения качественной продукции для населения (яйцо, мясо, печень) [1-25].

Многолетние собственные наблюдения свидетельствуют, что в целях удешевления комбикормов часто используются более дешевые компоненты, необоснованно завышенные матрицы питательности на ферментные препараты, премиксы и другие биологически активные добавки, которые невозможно проверить, в отличие, например, от параметров питательности компонентов комбикормов, а это те же матрицы (протеин, жир, клетчатка и т.п.), которые мы контролируем в кормах. Такие рационы обычно рассчитаны на объемное кормление птицы (для кур это 125 г/ гол./сут. и более). При этом некоторые производители премик- сов, оказывающие консультативное сопровождение, предлагают специалистам использовать для таких комбикормов более дешевые премиксы с пониженной нормой витаминов и микроэлементов в расчете на то, что, с повышенной нормой дачи низкопитательного комбикорма в расчете на голову птица получит свою суточную потребность в витаминах и микроэлементах, забывая о том, что низкопитательные комбикорма хуже перевариваются и усваиваются, включая витамины и микроэлементы. В таких случаях быстрее всего несушки реагируют на недостаток витамина $\mathrm{D}_{3}$. Нередко на практике приходится видеть в составе комбикорма для кур премиксы, в которых уровень витамина $D_{3}$ составляет 2,5 млн. МЕ/т корма при норме расхода такого корма в расчете на голову 128-130 г. Теоретически птица должна получить при таком раскладе свою суточную потребность в витамине $D_{3}$, но на практике в одном из хозяйств оказалось, что наша рекомендация увеличить норму витамина $\mathrm{D}_{3}$ в премиксе хотя бы до 3,0 млн. ME/т комбикорма обеспечила дополнительный ежедневный сбор яйца в количестве 22 тыс. шт. После этого специалисты хозяйства стали закладывать в рецептуру премикса витамина $D_{3}$ не менее 3,5 млн. МЕ/т комбикорма. То же самое касается и других витаминов и микроэлементов. Помните, что рекомендуемые гарантийные нормы добавок, как витаминов, так и микроэлементов в комбикорм, в отличие от аминокислот, кальция, фосфора и натрия, не связаны с его питательностью и потреблением, а скорее зависят от вида, возраста птицы и направления продуктивности (промышленное, племенное птицеводство). Но если для пищевых яиц нет жестких нормативов по 
содержанию в них витаминов, то для инкубационных яиц они существуют (см. табл. 1).

При посещении птицефабрик неоднократно приходилось наблюдать более низкое содержание витамина А в желтке инкубационных яиц - 5,8 мкг/г, при том, что в премиксе было заявлено в расчете на комбикорм 15 млн. МЕ/т. Уровень витамина Е в желтке иногда не превышает 50 мкг/г, что, безусловно, будет влиять на кислотное число желтка, с чем тоже приходится сталкиваться (5,5-6,3 мг КОН/г), и негативно сказываться на результатах инкубации яиц и качестве суточного молодняка. Пример из собственного опыта: премиксы для бройлеров при заявленных 10 млн. ME/т корма витамина A обеспечили в печени цыплят при сдаче на убой в 36 дней всего 33-37 мкг/г витамина А, что в пределах показателей суточного цыпленка (29-45 мкг/г). Иногда в опытах мы получали 80-90 мкг/г витамина А в печени цыплят при убое, что тоже мало, хотя при такой норме витамина А в комбикорме и хорошем его качестве в печени бройлеров при убое витамина А должно быть не менее 140-160 мкг/г, что мы тоже получали в своей многолетней работе. Выраженных признаков гиповитаминоза А у бройлеров за столь короткий срок выращивания выявлено не было, но, безусловно, качество таких премиксов будет негативно сказываться на птице длительного использования - ремонтном молодняке и особенно курах-несушках, когда пойдет вынос витамина А с яйцом. Имеются сведения, что при содержании в корме витамина A в количестве 3250 ME/Кг в яйцах кур могут появляться кровяные пятна, что тоже встречается при производстве пищевых, а иногда и инкубационных яиц. Кровяные пятна в желтке появляются чаще у молодых несушек в результате разрыва капилляров. Для снижения количества таких яиц нужен контроль за содержанием не только витамина А в премиксе, но и витамина K $[23,25]$.

Признаком недостатка витамина $\mathrm{B}_{2}$ может быть разжиженный и обесцвеченный белок, шероховатая и пятнистая скорлупа.

Витамин $\mathrm{D}_{3}$ в яйце не определяется, но его недостаток, связанный с качеством скорлупы, начинает проявляться через 2-3 суток. Это выражается в снижении продуктивности кур за счет появления бесскорлупных яиц и в увеличении процента боя и насечки яиц. Затянувшийся дефицит витамина приводит к ухудшению состояния костяка. Дефицит витамина $D_{3}$ в комбикормах для племенных несушек, к тому же, приводит к снижению процента вывода цыплят по причине плохого окостенения клюва, что неоднократно приходилось наблюдать в условиях производства, при этом у вылупившихся цыплят кости ног мягкие, и они довольно быстро погибают изза ограниченной подвижности и невозможности подойти к кормушке и поилке.

При нарушении D-витаминного и минерального питания птицы существенно снижается зольность костей и содержание в них кальция и фосфора. У здоровых суточных цыплят содержание кальция в костях составляет 1012\%, фосфрора - 5-6\%; у 4-недельных 16-18 и 7-8\% соответственно. В берцовой кости кур, индеек, уток содержится 55-62\% золы, 2028\% кальция и 10-12\% фосфора. У 5-недельных бройлеров содержание золы в костях составляет 4244\%, кальция - 16-18\%, фосфора 7-9\%. Это вполне реальные данные, полученные в 21 веке на современных высокопродуктивных кроссах яичной (Хайсекс белый, Хайсекс коричневый, Родонит, Ломанн) и мясной (Кобб, Росс) птицы [24,25]. Однако нам неоднократно приходилось видеть костяк кур, содержащий 17-18\% кальция и 7-8\% фосфора. Как правило, у этих кур искривлен киль, плохое

Таблица 1. Рекомендуемые уровни витаминов и каротиноидов и некоторых других показателей качества инкубационного яйца птицы

\begin{tabular}{|c|c|c|c|c|c|c|}
\hline \multirow{2}{*}{ Показатели } & \multicolumn{6}{|c|}{ Вид птицы } \\
\hline & Куры & Утки & Гуси & Индейки & Перепела & Цесарки \\
\hline \multicolumn{7}{|l|}{ Содержание в желтке, мкг/г, не менее: } \\
\hline каротиноидов & 18 & 13 & 15 & 10 & 18 & 20 \\
\hline витамина А & 7 & 7 & 8 & 8 & 15 & 10 \\
\hline витамина E & 60 & 60 & 60 & 60 & 60 & 60 \\
\hline витамина $\mathrm{B}_{2}$ & 4 & 5 & 5 & 8 & 6 & 4 \\
\hline Содержание витамина В в в белке, мкг/г, не менее & 3,0 & 2,5 & 2,5 & 3,0 & 3,0 & 2,5 \\
\hline Кислотное число желтка, мг КОН/г, не более & 5 & 5 & 5 & 5 & 5 & 5 \\
\hline Толщина скорлупы, мм, не менее & 0,330 & 0,380 & 0,500 & 0,370 & 0,160 & 0,500 \\
\hline Упругая деформация яиц, мкм, не более & 25 & 22 & 20 & 22 & - & 18 \\
\hline
\end{tabular}


оперение и скорлупа низкого качества. В костях 36-38-дневных бройлеров содержание кальция нередко бывает 10-12\% и фосфора 5-6\%, что чревато переломами при транспортировке и убое птицы. Низкая зольность костей у кур приводит к остеопорозу со всеми вытекающими негативными последствиями для продуктивности, качества продукции и жизнеспособности поголовья.

Многолетние наблюдения авторов за качеством премиксов по результатам фактических анализов свидетельствуют, что в комбикормах часто не хватает витамина $\mathrm{D}_{3}$, что чревато серьезными экономическими потерями, включая потери от качества скорлупы и костяка. Например, при заявленных в премиксе в расчете на комбикорм 3,5 млн. МЕ/т в результате анализа чаще можно найти 2,8-
3,0 млн. МЕ/т, что хотя и укладывается в ошибку метода определения, но не устраивает птицу, которая реагирует на это снижением прочности скорлупы и увеличением процента боя и насечки яиц. Нередки случаи, когда при заявленных 3,5 млн. МЕ/т корма витамина $D_{3}$ анализом можно найти в премиксе всего 2,1 млн. МЕ/т. По другим витаминам при анализе премиксов ошибки метода также обычно бывают со знаком минус, а не плюс, что приводит к снижению их депонирования в яйцах и печени, нарушению углеводного, жирового и белкового обмена, минерализации костяка. При этом развиваются такие заболевания как нефриты, жировая дистрофия печени, рахит, остеопороз, некроз головки бедренной кости и т.п. В табл. 2 представлены пределы колебаний по содержанию витами- нов и макроэлементов в биологических объектах, обобщенные по птицефабрикам на основании исследований, проведенных во ВНИТИП.

Представленные в таблице результаты анализа биологических объектов, присланных во ВНИТИП с птицефабрик, свидетельствуют о большом разбросе всех показателей, что связано с качеством премиксов, комбикормов, физиологическим состоянием птицы, коррекцией общей питательности и минеральной составляющей комбикормов за счет матриц на ферментные препараты, премиксы и прочие добавки и т.п. Образцы с минимальными значениями показателей, как в яйце, так и в костяке и печени, а их было достаточно много, безусловно, свидетельствуют о проблемах, как с качеством и нор-

\begin{tabular}{|c|c|c|c|c|c|}
\hline \multicolumn{6}{|c|}{ Содержание витаминов в яйце, мкг/г } \\
\hline Вид птицы & A & $\mathrm{E}$ & $\mathrm{B}_{2} 6$ & желток & Каротиноиды \\
\hline Куры & $3,0-7,8$ & $31-429$ & 3,0 & $, 8-9,1$ & $5,1-29,1$ \\
\hline Гуси & 7,0 & 140 & & - & 3,1 \\
\hline Утки & $4,6-6,1$ & $41,8-126,7$ & \multicolumn{2}{|c|}{$0,31 / 13,9$} & $5,15-18,22$ \\
\hline Перепела & $5,4-9,3$ & $42,9-169,8$ & & - & $5,27-20,9$ \\
\hline Индейки & 5,1 & $24,0-101$ & \multicolumn{2}{|r|}{ - } & $2,14-13,94$ \\
\hline \multicolumn{6}{|c|}{ Содержание витаминов в печени, мкг/г } \\
\hline \multicolumn{3}{|c|}{ Вид птицы } & \multicolumn{2}{|c|}{ A } & $\mathrm{E}$ \\
\hline Бройлеры суточные & & & \multicolumn{2}{|c|}{$18-40$} & $900-1500$ \\
\hline Бройлеры 3-неделью & & & \multicolumn{2}{|c|}{$45-90$} & $25-40$ \\
\hline Бройлеры при убое & & & \multicolumn{2}{|c|}{$80-200$} & $15-25$ \\
\hline Ремонтный молодня & & & \multicolumn{2}{|c|}{31,1} & $42,2-51$ \\
\hline Взрослые куры & & & \multicolumn{2}{|c|}{$590-1215$} & $16,4-72,3$ \\
\hline Утята суточные & & & \multicolumn{2}{|c|}{$29,0-37,0$} & $289-299$ \\
\hline Перепелята суточны & & & \multicolumn{2}{|c|}{$22,0-25,5$} & $179-229$ \\
\hline Индюшата суточные & & & \multicolumn{2}{|c|}{$27,3-46,4$} & - \\
\hline Взрослые индейки & & & \multicolumn{2}{|c|}{$41-44$} & - \\
\hline \multicolumn{6}{|c|}{ Минерализация костяка, \% } \\
\hline \multicolumn{3}{|c|}{ Вид птицы } & Зола & Кальций & Фосфор \\
\hline Куры & & & $44,5-63,8$ & $17,3-23,8$ & $8,13-12,58$ \\
\hline Ремонтный молодня & & & $37,4-43,5$ & $14,4-14,9$ & $6,56-6,8$ \\
\hline Бройлеры & & & $33,4-51,5$ & $12,9-22,6$ & $6,67-9,16$ \\
\hline Бройлеры, патологи & & & $24,7-32,11$ & $9,45-13,2$ & $4,9-5,1$ \\
\hline
\end{tabular}


мированием витаминов, так и с реализацией генетического потенциала продуктивности птицы, поскольку на анализ во ВНИТИП образцы присылают обычно тогда, когда появляются проблемы.

В частности, из 80 проб инкубационных яиц кур в 58 пробах концентрация витамина А была ниже 7 мкг/г и т.п. Из табл. 2 видны патологические отклонения по содержанию других витаминов и каротиноидов в яйце и печени, а также по минерализации костяка. Прежде всего, это касается низкого содержания витамина А в печени ремонтного молодняка кур и взрослых индеек. При содержании витамина А в печени менее 800 мкг/г несушки вряд ли обеспечат достаточный его уровень в инкубационном яйце. В тоже время, хотя и редко, но встречались образцы яиц и печени с очень высоким содержанием витамина Е, что отчасти связано с использованием в комбикормах растительного масла, содержащего токоферол; также этому способствуют не всегда обоснованно высокие уровни витамина Е в премиксе, применяемые на всем протяжении выращивания бройлеров (до 200 г/т) и содержания несушек (до 100-200 г/т). Обращает на себя внимание и большой разброс данных по содержанию каротиноидов в яйце, что, очевидно, в большинстве случаев связано с отсутствием или низким уровнем в комбикормах кукурузы, кукурузного глютена и травяной муки. Если на этом фоне использовать премиксы с пониженной нормой ввода витаминов и минералов в расчете на объемное кормление птицы, то хороших результатов инкубации таких яиц получить невозможно.

Разброс данных по содержанию витамина $\mathrm{B}_{2}$ в белке и желтке также отчасти связан с рецептурой и питательностью комбикор- ма с одной стороны или с низким его содержанием в премиксе и низкой биологической доступностью - с другой. Часто приходится видеть заниженные нормы холина, взятые без учета его содержания в препарате [14].

Из представленных данных вытекают следующие выводы: 1) о необходимости контроля качества премиксов; 2) если нормы ввода витаминов в премиксы корректируются в сторону снижения В расчете на объемное потребление комбикорма пониженной питательности, то от этой практики следует отказаться; 3) нормирование витаминов необходимо проводить с учетом содержания активно действующего вещества; 4) если появляются проблемы со скорлупой или костяком, то необходимо, прежде всего, выпоить птице водорастворимую форму витамина $\mathrm{D}_{3}$, ответная реакция на которую в случае проблем со скорлупой начинает проявляться уже в течение первых 24-48 ч после выпойки [23].

Сотрудниками ООО «НВЦ Агроветзащита» разработаны и предложены производству водорастворимые витаминные препараты и комплексы, которые прошли широкие научные и производственные испытания [16-20,22,24]. Прежде всего, это водорастворимый препарат витамина $\mathbf{D}_{3}$, который предназначен для применения в качестве «скорой помощи» при проблемах с качеством скорлупы и костяка у птицы. Препарат содержит в 1 мл 15 тыс. МЕ витамина $D_{3}$. Норма расхода препарата составляет 100 мл/т воды.

Препарат Волстар в 1 мл содержит: витамин А - 50 тыс. МЕ; витамин $D_{3}-2$ тыс. МЕ; витамин Е - 30 мг; витамин C - 100 мг, а также вспомогательные вещества, способствующие его хорошей растворимости. Норма выпойки составляет 0,5 л/т воды.
Препарат ВитОкей в 1 мл содержит: витамин А - 10 тыс. МЕ, $\mathrm{D}_{3}$ - 2 тыс. $\mathrm{ME}, \mathrm{E}-10 \mathrm{мг,} \mathrm{K}-2 \mathrm{Mг}$, $\mathrm{B}_{1}-10 \mathrm{Mr}, \mathrm{B}_{2}-4 \mathrm{Mr}, \mathrm{B}_{3}-20 \mathrm{Mr}, \mathrm{B}_{5}-$ $30 \mathrm{мг}, \mathrm{B}_{6}-3 \mathrm{Mr}, \mathrm{BC}-0,2 \mathrm{Mr}, \mathrm{B}_{12}-10$ мкг, биотин - 10 мкг и вспомогательные компоненты. Норма расхода составляет, в зависимости от вида и возраста птицы, 0,2-1,0 л/т воды.

Продолжительность и кратность применения указанных препаратов составляют 3-5 дней один или два раза в месяц, в зависимости от состояния птицы.

\section{Литература}

1. Болезни птиц / Б.Ф. Бессарабов, И.И.Мельникова, Н.К. Сушкова [и др.]. СПб-М., 2009. - 448 с.

2. Околелова Т.М., Румянцев С.Д., Кулаков А.В. [и др.] Корма и биологически активные добавки для птицы. - М.: Колос, 1999. - 96 с.

3. Околелова Т. Актуальные вопросы в кормлении птицы // Животноводство России. - 2009 - №5. - С. 21-22.

4. Околелова Т.М., Енгашев С.В. Роль кормления В профилактике незаразных болезней птицы. - М.: РИОР, 2019. - 268 c.

5. Бессарабов Б.Ф. Болезни сельскохозяйственной птицы. - М.: Колос, 1973. - 184 c.

6. Околелова Т.М., Шарипов Р.И. Актуальность применения биологически активных веществ и производства премиксов в птицеводстве. - Алматы: Альманах, 2017. - 218 с.

7. Околелова Т.М., Енгашев С.В., Салгереев С.М. Причины отложения мочекислых солей в организме птицы // Птицеводство. - 2017. - №10. С. $47-50$

8. Околелова Т.М., Шарипов Р.И., Шарипов Т.Р. Болезни, возникающие при неправильном кормлении и содержании птицы. - Алматы: НурПринт, 2018. - 262 с.

9. Околелова Т.М., Салимов Т.М. Биологически активные и минеральные добавки в питании птицы. - Душанбе: Суфра, 2018. - 256 с. 
10. Околелова Т.М., Мансуров Р.Ш., Хребтова Е.В., Ребракова Т.М. [и др.] Нужна ли выпойка витаминных препаратов курам? // Птицеводство. 2014. - №8. - С. 25-29.

11. Подобед Л.И., Околелова Т.М. Диетопрофилактика кормовых нарушений в интенсивном птицеводстве. Часть 2. - Одесса: Печатный дом, 2010. - 298 c.

12. Кормовые и технологические нарушения в птицеводстве и их профилактика / Л.И. Подобед, В.И. Фисинин, И.А. Егоров, Т.М. Околелова. Одесса: Акватория, 2013. - 496 с.

13. Околелова Т.М. Что нужно знать о качестве сырья и биологически активных добавках. - Сергиев Посад, 2016. - 280 c.

14. Околелова Т.М., Енгашев С.В., Салгереев С.М. Факторы питания, влияющие на состояние органов яйцеобразования // Птицеводство. 2017. - №8. - С. 37-39.

15. Биологически активные и кормовые добавки в птицеводстве: метод. рекомендации / В.И. Фисинин, Т.М. Околелова, И.А. Егоров [и др.]. Сергиев Посад: ВНИтиП, 2009. $100 \mathrm{c}$.

16. Околелова Т.М., Енгашев С.В., Ен- гашева Е.С., Салгереев С.М. [и др.] Что дает дополнительная выпойка витамина Д высокопродуктивным несушкам? // Птицеводство. - 2019. - №3. С. 29-34.

17. Околелова Т.М., Енгашев С.В., Егоров И.А. Птицеводство: Актуальные вопросы и ответы. - М.: РИОР, 2020. - 268 c.

18. Околелова Т.М., Шарипов Р.И., Шарипов Т.Р. Кормление сельскохозяйственной птицы в вопросах и ответах. - Алматы: Нур-Принт, 2019. $250 \mathrm{c}$.

19. Енгашев С.В., Околелова Т.М., Енгашева Е.С., Лесниченко И.Ю. [и др.] Применение препаратов, повышающих продуктивность птицы при производстве экологически безопасной продукции // Ветеринария. - 2019. №9. - С. 46-50.

20. Околелова Т.М., Енгашев С.В., Енгашева Е.С., Лесниченко И.Ю. Профилактика дефицита витамина Д у кур // Птица и птицепродукты. - 2019. - №5. C. 58-60.

21. Рекомендации по кормлению сельскохозяйственной птицы / Ш.А. Имангулов, И.А. Егоров, Т.М. Околелова [и др.]. - Сергиев Посад: ВНИтИП, 2009. $144 \mathrm{c}$.
22. Методические рекомендации по использованию препаратов, стимулирующих продуктивность и сохранность птицы, повышающих качество продукции / С.В. Енгашев, Т.М. Околелова, Е.С. Енгашева [и др.]. - М.: РИОР, 2020. - 44 C.

23. Основные факторы улучшения качества куриных яиц. - Боровск, 2008. - 26 с.

24. Околелова Т.М., Енгашев С.В. Научные основы кормления и содержания птицы. - М.: РИОР, 2021. 439 c.

25. Околелова Т.М., Маркелова Н.Н. О проблемах минерального питания современных высокопродуктивных кроссов кур // Птицеводство. 2012. - №4. - С. 26-28.

Для контакта с авторами:

Околелова Тамара Михайловна

E-mail: tokolelova@vetmag.ru

Енгашев Сергей Владимирович

E-mail: sve@vetmag.ru

Лесниченко Ирина Юрьевна

Тел.: 8-495-648-26-26

Шевяков

Александр Николаевич

Хребтова Елена Владимировна

E-mail: alex.shevy@mail.ru

\title{
Risks Related to the Quality of Vitamin Premixes for Poultry and Their Prevention
}

Okolelova T.M.' ${ }^{1}$ Engashev S.V. ${ }^{1}$, Lesnichenko I.Yu. ${ }^{1}$, Shevyakov A.N. ${ }^{2}$, Khrebtova E.V. ${ }^{2}$

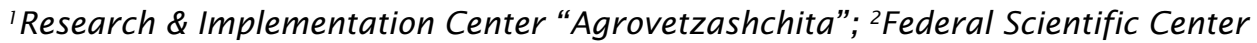 \\ "All-Russian Research and Technological Institute of Poultry" of Russian Academy of Sciences
}

\begin{abstract}
Summary: The role of the quality of premixes in poultry nutrition and its effects on the realization of genetic productivity potential are reviewed. The responses of poultry to the deficits of different vitamins and factors affecting the requirements in vitamins and trace elements of different productive groups are described. The biochemical criteria of the quality of eggs for incubation of different poultry species and reference values of the contents of certain vitamins $(A, E)$ in liver are presented. The recommendations on the control of the provision with vitamin $D_{3}$ via bone mineralization parameters (the contents of ash, calcium, and phosphorus) in different poultry species and groups are provided. The data on the efficiency of vitamin nutrition obtained by the analyses of liver, eggs, bones are summarized. The possible reasons of insufficient supply of vitamins $A$, $B_{2}$, and $D_{3}$ are presented. The identification of the hypovitaminoses should be primarily based on the analyses of the real contents of vitamins in premixes and in eggs, liver, and bones; these conditions can be effectively and promptly prevented by the periodic supplementation of drinking water for poultry with water-soluble complexes of vitamins.
\end{abstract}

Keywords: poultry, vitamins, premixes, hypovitaminoses, liver, eggs, bones. 